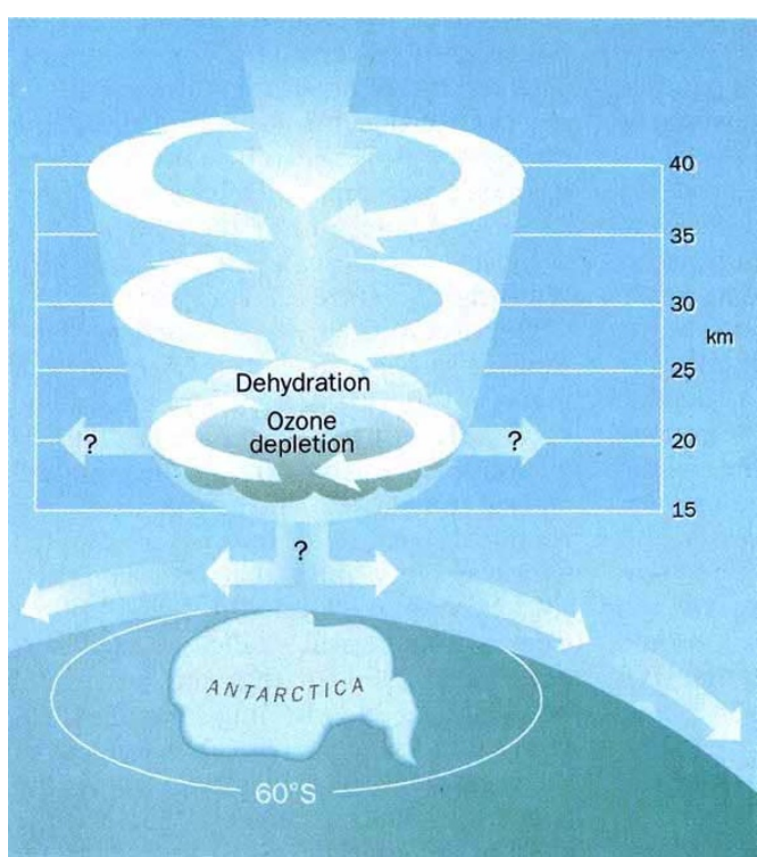

The Antarctic polar stratospheric vortex in middle to late winter; the vertical scale is exaggerated by a factor of about a hundred. The vortex is defined by the stratospheric jet-stream winds circulating about the South Poie (with maximum speeds near $100 \mathrm{~m} \mathrm{~s}^{-1}$ in the upper stratosphere in mid-winter), and by the associated horizontal gradients of potential vorticity ${ }^{1-3}$. Air flows strongly downwards into the vortex above $40 \mathrm{~km}$. The rate of horizontal and vertical flux out of the vortex below $25 \mathrm{~km}$ is the focus of the debate over whether the vortex is a 'flowing processor' or a 'containment vessel'. Dehydration and ozone depletion both occur in the lower stratosphere at heights between about 15 and $25 \mathrm{~km}$. Both are ultimately due to the intense cold within the vortex at this height (below $-80^{\circ} \mathrm{C}$ ): dehydration results directly from freeze-out of water vapour, ozone depletion from chlorinecatalysed processes which in turn occur primarily in the presence of polar stratospheric clouds (composed of ice or hydrates of nitric acid).

this tendency would be balanced by infrared radiative cooling of the lower stratosphere.

Do the measurements bear this out? Preliminary estimates of these descent rates from the HALOE data, based on the vertical displacements of the dehydrated region within the vortex during one week in mid-October (after temperatures have risen above the frost point) look promising $(1.7 \pm 0.3$ kelvin per day, near 19 kilometres; Tuck). But extensive aircraft observations of the long-lived tracer $\mathrm{N}_{2} \mathrm{O}$ in the Antarctic vortex during August and September 1987 showed little vertical variation with time, suggesting cooling rates less than 0.2 kelvin per day ${ }^{5,6}$. Furthermore, similar small values are derived from independent calculations of the radiative cooling rates in the polar lower stratosphere 7,8 (which, as noted above, must balance the descent rates in equilibrium).

The difference between the rival descent rates may be attributable to the shorter time record analysed by HALOE, together with the fact that vortex descent rates are highest during late spring (October). But it seems difficult to reconcile the earlier $\mathrm{N}_{2} \mathrm{O}$ observations and current radiative transfer calculations with the strong flow out of the bottom of the vortex needed throughout the entire winter to produce the mass flux proposed by Tuck.

The HALOE observations of hemispheric-scale dehydration in the Southern Hemisphere present atmospheric scientists with an intriguing problem. Matters may become clearer with further analyses of a new general circulation model simulation of the stratospheric water vapour budget, which shows midlatitude dehydration in the southern stratosphere similar to that observed by $\mathrm{HALOE}^{9}$ (although the transport mechanism remains to be established).

Transport of vortex air to mid-latitudes would leave other clues to its presence. Decreasing concentrations of ozone have been observed over mid-latitudes of both hemispheres, and this as yet unexplained observation may be a signature of vortex processing. This may be more likely in the Northern Hemisphere stratosphere $^{10}$, where the downward circulation in the vortex is stronger than that in the south. Although dehydration is not widespread in the Northern Hemisphere vortex because the air is too warm, the CLAES and MLS instruments, also on board UARS, have been looking for tell-tale signs of vortex processing in the concentrations of other trace gases. When the results are analysed in detail, we can expect fresh contributions to the debate.

William Randel is at the National Center for Atmospheric Research, Boulder, Colorado 80307, USA.

1. Schoeberl, M. E. etal. J. geophys. Res. 97, 7859-7882 (1992)

2. Tuck, A. F. J. geophys. Res. 94, 11687-11737 (1989)

3. Juckes, M. N. \& Mclntyre, M. Nature 328, 590-596 (1987).

4. Bacmeister, J. T. \& Schoeberl, M. R. Geophys. Res. Lett 19, 1101-1104 (1992)

5. Hartmann, D. et al. J. geophys. Res. 94, 16779-16796 (1989)

6. Lowenstein, M. etal. J. geophys. Res. 94, 11589 $11598(1989)$

Shine, K. O.JIR met. Soc. 115, 265-292 (1989)

8. Rosenfield, J. et al. J. atmos. Sci. 44, 859-876 (1987)

9. Mote, P. W. et al. Geophys. Res. Lett. (in the press)

10. Stolarski, R. S. etal. Science 256, 342-349 (1992)

\section{Outfacing time}

'YoutH'S a stuff will not endure', at least facially. The encroaching lines and wrinkles of maturity fill many of us with dismay. Some of us are so dismayed that we even seek surgical help.

In the standard face-lift, the surgeon removes a chunk of skin and stretches the rest to fill its place, thus ironing out the wrinkles. The procedure may seem rather drastic, but has nature on its side. In the normal process of wound-healing. the dermis contracts around the region of damage; so the surgeon can rely on a useful automatic reduction of skin area. Even so, the removal of one big chunk of skin, and the stretching of the rest, tends to distort the patient's features. One way of avoiding this might be to remove very many small areas of skin, distributed evenly over the region to be smoothed. Daedalus is now taking the idea to extremes. He proposes to remove millions of micron-sized regions of dermis, each too small to see.

He has been inspired by the technology of grit-blasting with solid carbon dioxide. It is surprisingly gentle. The tiny particles chip away dirt and dust from the object to be cleaned, and then evaporate perfectly to leave no residue. Solid carbon dioxide seems a bit drastic as a facial abrasive, but micron-sized pieces of ice (or better, frozen medical saline solution) should do the trick nicely. So the DREADCO Wrinkle Blaster is a sort of small-scale thunderstorm. It grinds ice into many tiny particles, and charges and accelerates them in a big electric field. The resulting miniaturized hailstorm is directed onto the subject's skin. Each particle penetrates a fraction of a millimetre, just sufficient to traverse the epidermis and enter the dermis. (There is a ballistic immunizer that works this way.) The ice melts and the microscopic lesion soon heals, with the normal contraction of dermal healing. The skin is fractionally tightened at that point, and the epidermis reforms scarlessly over the tiny wound. The millions of tiny pinpricks contract the whole region of skin, evenly and strongly.

Thus the facial clock will be put back, and the cruel marks of time erased. Wrinkle Blasting will certainly sting severely, but may not need a local anaesthetic. Daedalus even hopes that the patient can control the whole treatment. DREADCO could then market the Wrinkle Blaster as a consumer product, for private facial maintenance and editing. Wrinkles may best be blasted in many small, controlled stages. The resulting slow and subtle facial rejuvenation will then arouse appreciation but no suspicion in friends, associates and lovers. David Jones 